UDK 784.3(497.12) Pavčič

\title{
SAMOSPEVI J. PAVČIČA
}

\section{Manica Špendal (Maribor)}

Pavčičev $0^{1}$ ustvarjanje se je začelo konec 19. stoletja oziroma na začetku 20. stoletja, v času, ko so slovenski skladatelji prizadevno gradili temelje slovenske kulture. Z njegovim nastopom, pa z nastopom A. Lajovca, E. Adamiča in G. Kreka, je slovenska glasba dobila nov impulz, ki je bil blizu sodobnim dosežkom evropskega Zahoda. Njihova dela so bila tehnično neoporečna, pri tem pa so se poglabljali še v značilnosti slovenske ljudske glasbe. Omenjeni skladatelji so postali nosilci naprednih slovenskih ustvarjalnih hotenj časa. Ob Lajovcu in Adamiču se je zdel Pavčič najbolj obetavni sodelavec glasbene revije Novi akordi. Meditem, ko sta bila prva dva $v$ bistvu sicer še romantika in njune skladbe kažejo že prvine novejšega oblikovalnega nazora, je Pavčič ostal vseskozi romantik.

Slovensko glasbeno literaturo je obogatil s klavirskimi skladbami in zbori, predvsem pa z nekaj izvrstnimi primeri s področja samospeva. Vsa Pavčičeva dela niso bila objavljena, delno so še neznana, vendar že izdane skladbe zadoščajo za jasno stilno in izrazno podobo njegovega kompozicijskega stavka. Krek je že ob natisu njegove klavirske skladbe »Stara pesem" ugotovil tenkočutnost skladateljevega izraza, ki se mu je zdela pomembna tudi za njegovo nadaljnje ustvarjanje. ${ }^{2}$ $\mathrm{Ob}$ izidu prvih dveh samospevov »Pastirice " na besedilo I. Robide in »Pred durmi« na tekst S. Jenka leta $1910^{3}$ je Krek izrazil upanje, da

$1 \mathrm{Za}$ biografske podatke gl. SBL II, 271.

2 Prim. Krek G., NA 1910, IX, 23.

3 Skladbi je izdala GM ljubljanska v zbirki »Osem samospevov s spremljevanjem klavirja «, v kateri so bile natisnjene še pesmi A. Lajovca, E. Adamiča in V. Flögla. "Pastirica « je izšla še 1. 1955 pri DZS v izdaji »Samospevi za visoki glas«, ki jo je uredil Danilo Švara, in v zbirki »Deset samospevov" v založbi GM 1. 1921, samospev "Pred durmi« pa samostojno 1. 1932 pri GM. Obe pesmi zasledimo tudi na koncertnih sporedih $\mathrm{v}$ Ljubljani in drugih slovenskih krajih: "Pred durmi« je bila do 1.1914 izvedena kar trikrat (Prim. NA 1912, XI, 21; NA 1914, XIII, 10, 12.). Pred citiranima samospevoma je Pavčič zložil le eno skladbo te vrste (l. 1889): „V ljubem si ostala kraji na tekst S. Jenka, ki je ohranjena v rokopisu. 
je mogoče od skladatelja »še veliko pričakovati« in da »ima dovolj lastnih sil za oblikovanje svojega izraza«, če se bo otresel vplivov. Pri tem je omenil Schuberta, Schumanna in Brahmsa. ${ }^{4}$

Za samospev »Pesem«, ki ga je bil Pavčič napisal na tekst K. Šulerjeve in ki je izšel kot prva skladba te kompozicijske vrste v Novih akordih leta 1911 (X, št. 2), je Krek dejal, da se bo moral pianist z lahko roko oprijemati tega samospeva, zlasti tam, »kjer ilustrira spremljava ptičkino žvrgolenje«, upa pa, da ta »rožica ne zvene tako hitro, kakor pesnikova «. ${ }^{5}$ Skladba je oblikovana enostavno in logično, preprost, vendar domiseln je tudi harmonski stavek, še zlasti vzorna je klavirska spremljava, ki se lepo sklada s pevsko linijo in veliko pri-
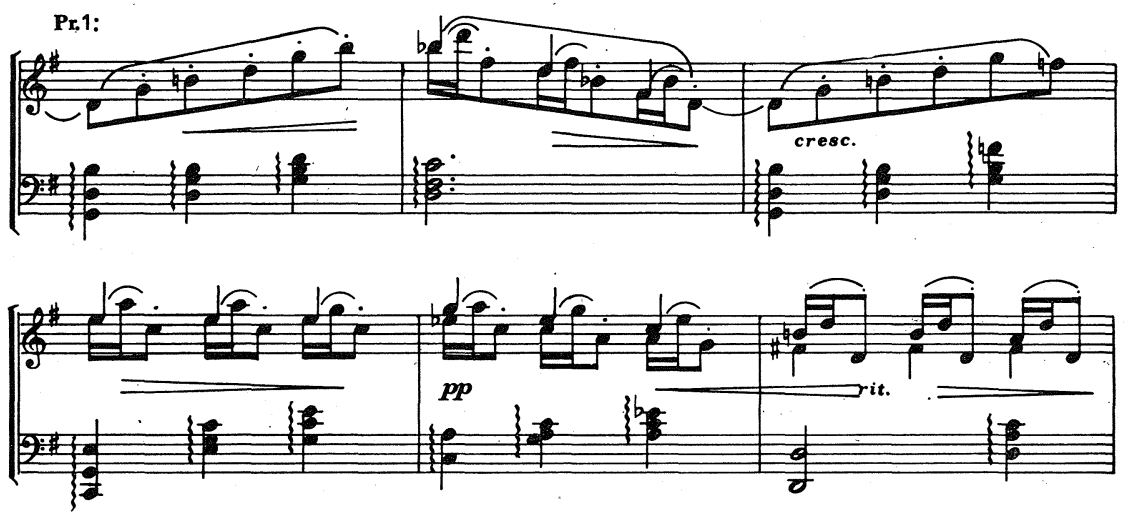

pomore $\mathrm{k}$ celovitosti dela ${ }^{6}$ »Pesem « so poleg Kreka ugodno ocenili tudi drugi slovenski glasbeniki, med njimi E. Adamič. Označil jo je kot »lahko in ljubko « skladbo, ki »pridobi takoj pevca in poslušalca «. ${ }^{7}$

Izreden uspeh je Pavčič imel z uglasbitvijo Župančičeve pesmi »Padale so cvetne sanje (iz pesniške zbirke »Čaša opojnosti«). Izšla je kot njegov drugi samospev v Novih akordih leta 1913 (XII, št. 1). Tudi Kreku je bila skladba zelo všeč. O njej se je izrazil, da je »ena najboljših doslej objavljenih skladb tega pridnega, previdno napredu-

4 Prim. Krek G., NA 1911, X, 22. - Miloje Milojević piše v svoji kritiki, da ga Pavčič spominja na nemškega skladatelja Petra Corneliusa. O »Pastirici« pa Krek meni, da je »divna pesem, polna pokreta«. Prim. Slovan 1911, IX, 384.

5 Prim. Krek. G., NA 1911, X, 26.

6 Posebno lepo zamišljena je ritmična figura od 11. takta dalje (pr. 1), s katero skladatelj ilustrira ptičje petje. (Gl. o tem tudi Premrl S., DiS 1911, XXIV, 199.)

7 Adamič še meni, da »četudi je, kakor rečeno, stvarica skkromna, vendar je zaradi umetniške vsebine ne smeta ne pevec ne spremljevalec bagatelizirati«. (Prim. Adamič E., LZ 1911, XXXI, 222).) — »Pesem« sta izvajali pev'ki I. Hrastova (I. 1913) in Severjeva (I. 1915) Prim. NA 1913, XII, 55; DiS 1915, XXXIV, 32. 
jočega skladatelja«, v katerem »spe velike, večje nade in obljube«. ${ }^{8}$ Samospev sodi $\mathrm{v}$ sam vrh Pavčičevega ustvarjanja na tem kompozicijskem področju. ${ }^{9}$ Tekst $O$. Župančiča je v njem idealno prestavil v glasbeno podobo, ki je po umetniški vrednosti na enaki ravni s pesnitvijo. Napisana je v vsakem pogledu vzorno. Formalno je jasna, ${ }^{10}$, odlikujejo jo izvirna melodična invencija, dosledno in logično izpeljani harmonski postopi in mojstrsko napisana klavirska spremljava (pr. 2), ki kaže izreden skladateljev čut za klavirski stavek. Izvrstno se prilega $\mathrm{z}$ melodično linijo in se $\mathrm{z}$ njo povezuje $\mathrm{v}$ celoto. ${ }^{11}$

\section{Pr. 2:}
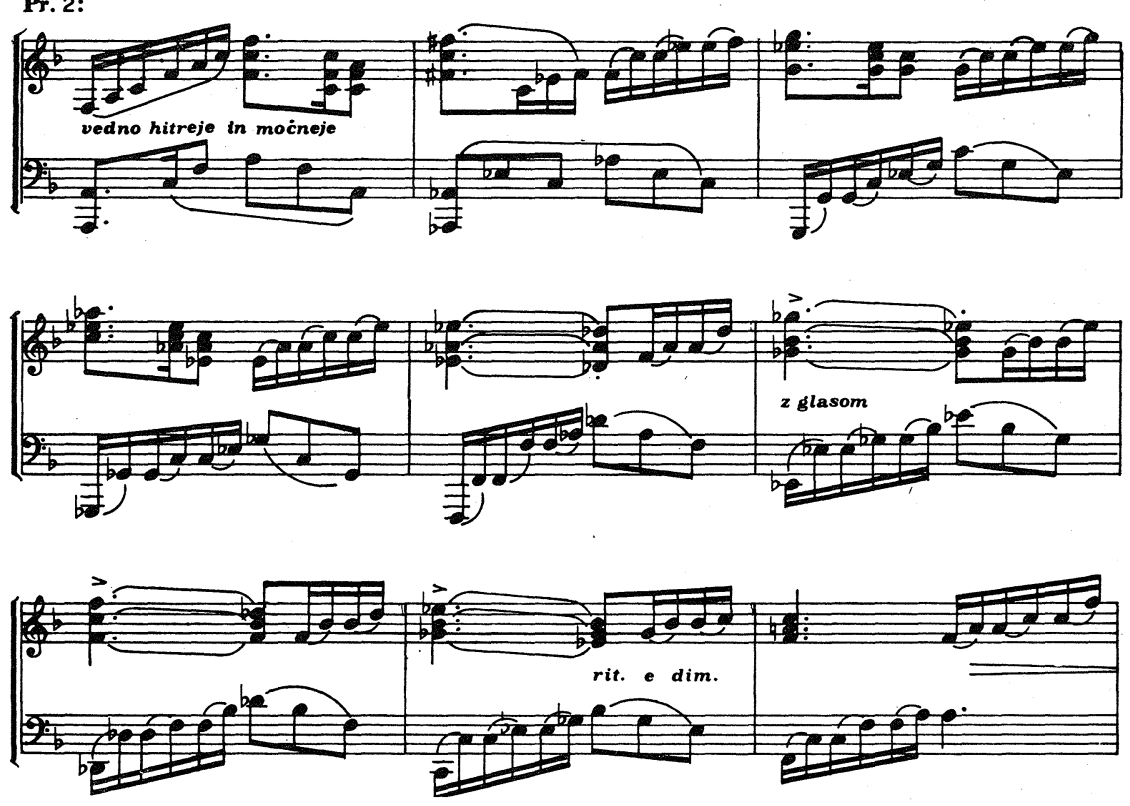

8 Prim. Krek G., NA 1913, XII, 10.

9 Gl. o tem tudi Lipovšek M., Ob 70-letnici Josipa Pavčiča, LZ 19401941, LZ, 624. - Podobno kot Krek je ocenil samospev S. Premrl, ki je o njem menil, da je »jako fina skladba s klavirjem « in jo »smemo prištevati med najboljše dosedaj objavljene Pavčičeve samospeve«. (Prim. Premrl S., DiS 1913, XXVI, 199.). Tudi P. Kozina se je pohvalno izrazil o Pavčičevi pesmi: "Kar se tiče solospevov, nismo ravno na slabem, imamo jih že lepo zbirko najboljše kvalitete, ali malo jih je, kateri se po svoji krasoti in hvaležnosti za pevca lahko primerjajo s Pavčičevo ,Padale so cvetne sanje'«. (Prim. Kozina P., LZ 1914, XXXIV, 342.)

10 Zložena je $v$ štiridelni obliki ABCD. V D delu je zadnjih sedem taktov nekaka reminiscenca na prvi A del, ki ima pomen kode.

11 Skladba je izšla še 1. 1955 v zbirki »Samospevi za visoki glas« v redakciji D. Švare. Pritegnila je tudi slovenske pevske umetnike, kar kažejo koncertni sporedi iz tega časa. Dve leti po izidu je bila trikrat izvedena, dvakrat jo je pela P. Lovšetova in enkrat P. Kozina. (Prim. NA 1913, XII, 47; NA 1914, XIII, 13.) 
Da so bile Pavčiču pesmi O. Župančiča posebno drage, kaže še vrsta nadaljnjih uspelih uglasbitev na njegova besedila: leta 1917 sta v ediciji Glasbene matice izšli najprej »Uspavanka $\mathrm{I}_{« 12}$ in (Ciciban Cicifuj«, leta 1921 pa je Glasbena matica izdala zbirko »Deset samospevov«, v katerih so kar štiri skladbe napisane na Župančičeve tekste, poleg že objavljene pesmice »Ciciban - Cicifuj« še »Uspavanka II«, »Dedek samonog«, »Serenada", »Vrabci in strašilo«. Nadalje so v tej zbirki tudi samospevi »Kaj mi pravi ptiček« (na tekst D. Ketteja), »Priplula je pomlad« (na besedilo S. Gregorčiča), »Prvi poljub« (na tekst K. Radiča), »Ženjica« (na tekst F. Kozaka) in že prej natisnjena »Pastirica (na tekst I. Robide).

Izmed citiranih samospevov so bili še posebej popularni tisti, ki so bili napisani na besedila Župančičevih pesmic iz pesniške zbirke »Ciciban in še kaj«, »Dedek samonog«, »Ciciban - Cicifuj«, »Vrabci in strašilo" in »Mehurčki«.13 Skladatelj jih je sprva zložil za sopran, tako kot večidel svojih samospevov. Šele pozneje je nekatere skladbe predelal za druge glasove. M. Lipovšek ugotavlja, da ga je »trenutno navdušil lep glas kake pevke, za katero je tudi predvsem pesem komponiral«. Domneva, da sta bili to »zlasti Suvova in Pavla Lovšetova«, ki imata $» v$ tem pogledu mnoge zasluge ${ }^{14}$

M. Lipovšek med drugim tudi ugotavlja, da je hotel Pavčič v svojih samospevih »prikazati vriskajoče pesmi ptic $\mathrm{v}$ gozdu, zibanje

12 »Pesem« je še pred izidom (1. 1917) pela na koncertu GIM P. Lovšetova, kot izvemo iz poročila S. Premrla, ki jo iznačuje kot »preprosto, a ljubko kitično pesmico«. (Prim. Premrl S., DiS 1916, XXIX, 162.)

13 Pesmico je Pavčič verjetno napisal v istem času kot »Uspavanko I«, kar lahko sklepamo iz poročila o koncertu GIM iz 1. 1916, kjer omenja avtor članka S. Premrl obe skladbi. Vendar so izšli »Mehurčki« v samostojni izdaji GM šele 1. 1944. (Prim. Premrl S., DiS 1916, XXVII, 162.) - Skladbo je pozneje za glas in orkester priredil L. M. Škerjanc. (rkp. prireditelja 1930.)

14 Prim. Lipovšek IM., ib., 623-624. - Iz 'koncertnih poročil in kritik je razvidno, da je zlasti $P$. Lovšetova zelo uspešno interpretirala Pavčičeve samospeve. S. Premrl npr. piše: ».... za ponovno lepo izvajanje zlasti Pavčičevih samospevov smo gospe Lovšetovi prav posebno hvaležni. ,CicibanCicifuj' je stal pred nami kot živa slika in še več: kot živ dogodek. ,Uspavanka' je bila nadvse ljubka, za tovrstne popevke je ga. Lovšetova kot nalašč ustvarjena. In zdravi smeh prebrisanega vrabca $\mathrm{v}$ pesmi ,Vrabci in strašilo' je moralo vsako pošteno dušo razveseliti.« (Prim. Premrl S., DiS 1919, XXXII, 170.) - Ugodne ocene sta za izvedbo Pavčičevih pesmi imela tudi J. Sadarjeva in J. Betetto. Največkrat sta bili na sporedu »Uspavanka I in II in »Ciciban - Cicifuj«. Kot kaže, so pesmi izvajali že v letih 1916 in 1919, torej še pred natisom 1. 1921. Skladbe iz zbirke »Deset samospevov«: „Ciciban - Cicifuj«, »Uspavanka I, II«, »Kaj mi pravi ptiček« so izšle še 1. 1955 v izdaji »Samospevi za visoki glas« v redakciji D. Švare, »Ženjica«, "Dedek Samonog" in "Priplula je pomlad" je isto leto (1955) izdala DZS pod naslovom »Samospevi za srednji glas«; »Ciciban - Cicifuj« pa je natisnjen tudi v Zborniku »Jugoslovanska solo pesma II« 1. 1961. »Ciciban Cicifuj« je za glas in orkester priredil L. M. Škerjanc (rkp. prireditelja 1932). 
klasja in pesmi škrjančkov na polju«. Zato meni, da ni »čudno«, da je Pavčič »prvi slovenski skladatelj, ki je uspešno in glasbeno neoporečno skladal za koloraturni sopran « ${ }^{15}$

Omenjene skladbe, zložene na Župančičeve pesmice, jasno kažejo, kako se je znal skladatelj vživeti $\mathrm{v}$ vsako razpoloženje in vsebinski značaj besedila in to tudi zelo posrečeno glasbeno oblikovati. Še zlasti je zajel v polni meri poetiko Župančičevega umetniškega izraza v samospevu »Dedek Samonog«. Po vsebini je pesmica preprosta in šegava in prav taka je tudi glasba: oblikovno preprosta, $v$ izrazu pa neposredna in lahko dojemljiva. Skladatelj nakaže vodilno glasbeno misel že $\mathrm{v}$ uvodnih taktih klavirskega dela (pr. 3). Grajena je na ležečem basu. V skladbi to misel večkrat ponovi in jo vsebini primerno variira $\mathrm{z}$ rahlimi ritmičnimi pa tudi melodičnimi spremembami $\mathrm{v}$ desni roki (pr. 4).
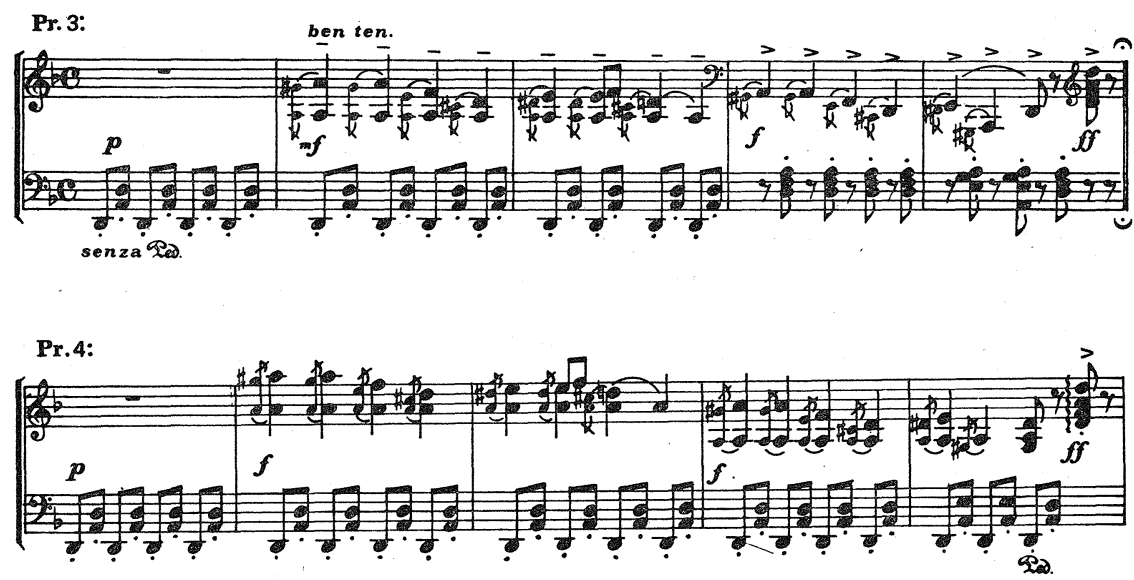

Trditi moremo, da so prav sijajne Pavčičeve uglasbitve Župančičevih pesmi pripomogle $\mathrm{k}$ veliki priljubljenosti pesnikove otroške zbirke »Ciciban in še kaj«, ki jo uživa še danes.

Pozneje je Pavčič objavljal svoje samospeve še $v$ nekaterih glasbenih revijah. ${ }^{16}$

15 Prim. Lipovšek M., ib., 623.

$16 \mathrm{~V}$ NIM 1928 (I, št. 1) je natisnjena njegova pesem »Ura« na tekst Utve (L. Prunkove), isto leto (1928) je založba Jug izdala njegovo »Sveto noč« na besedilo G. Ipavca; v Zborih (VI, št. 4) 1. 1930 in v zbirki »15 samospevov za glas s klavirjem《 1. 1933 (v založbi pevskega društva "Ljubljanski Zvon«) je izšel samospev "Mlada pesem" na tekst C. Golarja. Priredbe nekaterih Pavčičevih skladb, ki jih hrani glasbena zbirka v NUK, kažejo, da je skladatelj napisal še samospeva »Otožnost«, na besedilo ljudske pes- 
Pavčičevi samospevi, še zlasti tisti, ki jih je zložil na pesnitve O. Župančiča in morda še nekaterih (»Priplula je pomlad«, »Ženjica«), spadajo nedvomno med najboljša tovrstna dela $\mathrm{v}$ slovenski glasbeni literaturi. Po fakturi in izvirnosti izraza so izvrstni, in to jim je zagotovilo trajno mesto na sporedih slovenskih glasbenih prireditev. Skladatelj jih je večidel posvetil tedanjima slovenskima koncertnima pevcema $\mathrm{P}$. Lovšetovi in $\mathrm{J}$. Betettu. $\mathrm{V}$ njih ni iskal novih poti, to tudi ni bil njegov namen. ${ }^{17}$ Prikazati je hotel, kot meni M. Lipovšek, »ljubkost, slovensko sentimentalno otožnost, za katero se včasih sprašujemo, odkod se prikrade med naša občutja «. ${ }^{18}$

Posebno značilna je pri Pavčičevih pesmih klavirska spremljava, ki se vzorno sklada s pevsko melodijo. V njej je skladatelj dovolj "samoniklo ubral nova, sveža pota klavirskega parta v samospevu«, kot pravilno ugotavlja Lipovšek, saj je imel kot dober pianist »vse pogoje za obvladanje klavirskega stavka ${ }^{19}$ Pavčiču gre zlasti zaradi njegovih samospevov pomembno mesto $\mathrm{v}$ zgodovini slovenske glasbe. Osebno je bil skromen, značaj mu ni dovoljeval, da bi se bil uveljavljal kako drugače kot s svojo umetnostjo, zato ni dosegel toliko popularnosti, kot bi si jo bil s svojim ustvarjalnim delom zaslužil. ${ }^{20}$

mi »Gozdič je že zelen«, ki ga je za godalni orkester in bas instrumentiral L. M. S'kerjanc (rkp. prireditelja 1934), »Potrkan ples«, ki ga je za glas in orkester prav tako priredil L. M. Škerjanc (rkp. prireditelja 1934). V notni mapi 1975 (št. 4) je še »Kmečka balada« napisana na tekst O. Zupančiča. $\mathrm{V}$ glasbeno knjižni prilogi NA navaja pisec poročila o koncertu, ki je bil 1. 1912 (24. 9.) v Ribnici na Dol., da je pevka P. Tomšičeva izvajala Pavčičev samospev »Tožba«. (Prim. NA 1913, XII, 49, 50.)

17 Podobno je mislil tudi M. Kogoj v svoji sodbi o Pavčičevi zbirki "Deset samospevov«, ko jih je označil za »estetsko dobro izdelano muzi'ko sedanjosti manj odgovarjajočega stila, pa solidnega stavka.« (Prim. Kogoj M., DiS 1922, XXXV, 413.)

18 Po Lipovškovem mnenju bi se Pavčičeva skladateljska vrednost znatno dvignila, če bi bil »ustvaril še več šaljivih, šegavih in ritmično zanimivejših samospevov«. (Prim. Lipovšek M., ib., 624.)

19 Prim. Lipovšek M., ib., 624. - V pogledu Pavčičevega klavirskega stavka meni Lipovšek, da je »malo lisztovski« vendar je po njegovem mnenju bil Pavčič »med nami prvi, ki je tako skladal«. (Prim. Lipovšek M., Spominu Josipa Pavčiča, SGR 1951, I, 25.) - S. Premrl sodi, da se Pavčičevi samospevi odlikujejo »po izbranem, skrbno izdelanem klavirskem stavku, ki je že sam zase upoštevanja vredna umetnina«. (Prim. Premrl S., CG, 1921, XLIV, 114.) - Manj ustrezno ocenjuje Pavčičeve samospeve A. Gröbming, ki trdi, da je pri njih »težišče v glasu«, medtem ko ima klavir »podrejeno vlogo«. (Prim. Gröbming A., Josip Pavčič (8. VI. 1870-24. IX. 1949), NZ 1949, IV, 21.

20 Npr. v Zborniku slovenskih samospevov iz 1. 1953, ki ima naslov "Slovenski samospev od pričetka do moderne dobe «, manjka primerek Pavčičevega samospeva, čeravno bi vanj sodil. 


\section{SUMMARY}

Josip Pavčič began his creative career at the turn of the century, at a time when Slovene composers were doing their best to lay the basis of Slovene musical culture. Together with A. Lajovic and E. Adamič he became one of the most promising contributors to the "Novi akordi" review. Whereas the first two enriched their romanticism with elements of newer stylistic trends, Pavčič remained a romantic throughout. He wrote piano and choral works as well as some excellent lieder. As regards the development of this compositional form, Pavčič's lieder do not represent landmarks of their species; however, regarding their technical and expressive qualities, especially those on texts by O. Župančič (Flowery Dreams, Grandfather Oneleg, Ciciban - Cicifuj) and some others (Spring Has Arrived, The Woman-Harvester), they place Pavčič on an important position in the history of Slovene music. This can be supported by the great popularity of his lieder, a popularity that has continued up to the present. A good pianist, he showed a great sense for the piano part which enriches the vocal line broadening it up to a congruent whole. 